\title{
Identificação de atributos críticos de satisfação em um serviço através da análise competitiva do gap de melhoria
}

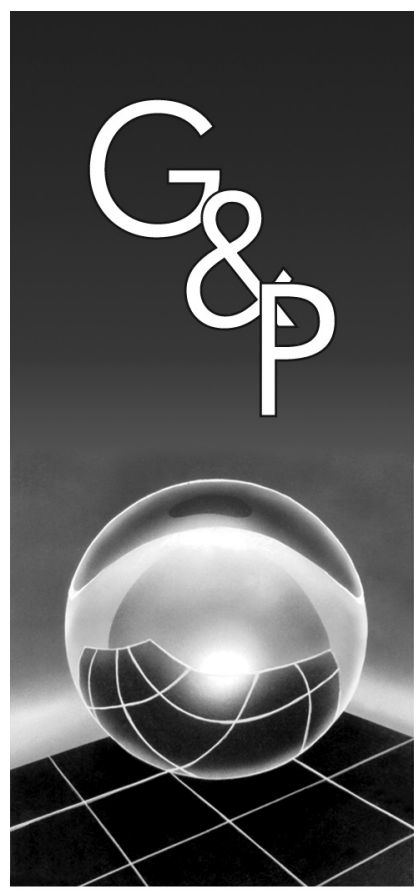

Gérson Tontini

André José Sant'ana

\section{Resumo}

O presente trabalho tem por objetivo apresentar um método para identificar atributos críticos para a satisfação do cliente e oportunidades de melhoria em bens e serviços em um mercado competitivo, reduzindo os problemas apresentados pela análise através da matriz de importância e desempenho proposta por Martilla e James (1977). Quanto a sua metodologia, a pesquisa foi do tipo exploratório-descritiva. A coleta de dados se deu em dois momentos. Inicialmente, foi realizada uma discussão com um grupo de foco com oito clientes de videolocadoras, procurando-se descobrir quais os atributos-chave para sua satisfação. Em seguida, 240 clientes de videolocadoras e alunos de graduação de uma instituição de ensino superior responderam um questionário modificado do modelo proposto por Kano et al. (1984). Para classificação dos atributos, segundo o Modelo Kano, foi utilizada uma análise de gap derivada do método proposto por Tontini e Silveira (2005). Dezenove atributos foram pesquisados, sendo que destes, quatro foram classificados como atrativos, dez como obrigatórios, dois como unidimensionais e três como neutros. Conclui-se que o método de gap corrigido, proposto neste trabalho, pôde auxiliar na identificação de atributos atrativos e obrigatórios para os clientes, permitindo priorizar quais deles deveriam ser objeto de melhoria e quais poderiam se tornar fonte de diferencial competitivo, superando algumas limitações da análise de importância $\mathbf{x}$ desempenho e do Modelo Kano tradicional.

Palavras-chave: Modelo Kano. Satisfação do consumidor. Qualidade em serviços. Gestão de qualidade.

\section{Introdução}

O impacto da satisfação dos clientes no sucesso das organizações tem sido amplamente discutido na literatura. Neste sentido, Anderson e Mittal (2000), estudando empresas que fazem parte do Barômetro de Satisfação do Consumidor Sueco, encontraram um aumento de $1 \%$ no índice de satisfação do consumidor associado ao aumento de 2,37\% no retorno sobre o investimento. Já um decréscimo de $1 \%$ neste índice estava associado a um decréscimo de $5,08 \%$ no retorno sobre o investimento. Assim, verifica-se que se é importante aumentar a satisfação do consumidor, é crítico evitar que ela diminua. Mas como uma empresa pode proporcionar satisfação contínua aos seus clientes? A satisfação está relacionada com o atendimento de necessidades explícitas e implícitas do consumidor, através do conjunto de características ou atributos do produto. Então, torna-se importante descobrir como o desempenho dos diferentes atributos está relacionado à satisfação dos clientes.
A maior parte das técnicas tradicionais que objetiva identificar a importância relativa dos atributos pressupõe que o consumidor tem experiência com o produto (DESZCA; MUNRO; NOORI, 1999). Isto se torna um limitador para a introdução de inovações, pois atributos inovadores tendem ter menor importância para o consumidor, devido ao desconhecimento dos seus benefícios. Além disso, as técnicas tradicionais pressupõem que a relação entre o desempenho dos atributos e a satisfação é linear, isto é, quanto maior o desempenho maior a satisfação, podendo levar a decisões errôneas na hora de se identificar quais atributos são críticos e quais ações devem ser tomadas para aumentar a satisfação dos clientes (HUISKONEN; PIRTTILÄ, 1998; TONTINI; SILVEIRA, 2005). O Modelo Kano de Qualidade Atrativa e Obrigatória (KANO et al., 1984) propõe que a relação entre desempenho e satisfação não é linear, classificando os atributos como obrigatórios (básicos), unidimensionais (performance) e atrativos 
(excitantes). Porém, o modelo não leva em consideração o atual nível de desempenho dos atributos, sendo limitado como uma ferramenta para identificação de oportunidades de melhoria da satisfação do consumidor.

$\mathrm{O}$ presente trabalho teve como objetivo comparar a análise através da Matriz de importância $\mathrm{x}$ desempenho (MARTILLA; JAMES, 1977) com o Modelo Kano de Qualidade Atrativa e Obrigatória, e propor uma melhoria no método proposto por Tontini e Silveira (2005) para identificação de atributos críticos para satisfação e oportunidades de melhoria em bens e serviços. O artigo está estruturado da seguinte forma: a seção 2 apresenta os procedimentos metodológicos usados neste artigo; a seção 3 apresenta os resultados da pesquisa, utilizando-se dos próprios dados da mesma para discutir as limitações da análise pela Matriz de importância $x$ desempenho e do Modelo Kano tradicional; a seção 4 ilustra as limitações do método proposto por Tontini e Silveira (2005) e introduz uma melhoria neste mesmo método e a seção 5 apresenta as conclusões do trabalho.

\section{Materiais e método}

A pesquisa foi realizada por meio de uma amostra de 240 alunos de graduação em Administração e clientes de videolocadoras. A amostra foi composta pelos alunos presentes na sala de aula no momento da aplicação do questionário, os quais aceitaram participar da pesquisa. Como os alunos provêm de diferentes regiões e classes sociais, e frequientam videolocadoras diferentes, considerou-se esta amostra como adeqüada para a realização do trabalho. Embora qualquer produto ou serviço pudesse ser objeto de estudo, pois se pretende aqui apresentar um método de análise e não um estudo exploratório, o serviço "videolocadoras" foi utilizado por ser de conhecimento geral dos respondentes.

Os atributos pesquisados foram identificados através de um grupo de foco com oito clientes de videolocadoras. Esses clientes foram escolhidos entre alunos voluntários que usavam freqüentemente este serviço. Por meio das discussões com os participantes e entrevistas semi-estruturadas por um questionário guia, 25 declarações foram sintetizadas pelo método de análise de conteúdo e agrupadas em nove necessidades primárias: 1) pertencer a um grupo; 2) ser visto como indivíduo; 3) conveniência de poder ver o filme a qualquer hora; 4) ganhar tempo na escolha; 5) sentir-se bem com as instalações; 6) poupar tempo no geral; 7) ter disponíveis os filmes que gosta; 8) escolher o filme que gosta; e 9) não ter experiência negativa na locação. Essas necessidades primárias foram agrupadas em três necessidades básicas: interação social, conveniência e lazer (Tabela 1). O agrupamento das declarações em necessidades foi realizado utilizando o método do diagrama de afinidades (MIZUNO, 1993), também conhecido como Método KJ (KAWAKITA, 1991) ou Language Processing Method (SHIBA, 1994).

No método do diagrama de afinidades, as declarações são sintetizadas e fundidas por afinidade semântica e intuitiva, em uma hierarquia com crescente grau de generalização. Segundo Mizuno (1993), as declarações e idéias dos participantes são escritas em cartões e estes agrupados por afinidade semântica, sem uma classificação prévia racional. Assim, as categorias que emergem das declarações não seguem uma lógica pré-concebida, podendo revelar a estrutura dos problemas.

A Tabela 1 mostra a relação entre as declarações dos participantes do grupo de foco sobre as videolocadoras e as necessidades primárias identificadas. A intensidade das relações (Forte - 6; Média - 3; e Fraca - 1) foi estabelecida por discussão entre os autores deste trabalho em uma análise qualitativa. Apesar de ser uma análise subjetiva, o estabelecimento deste relacionamento auxilia na priorização dos atributos a serem estudados.

As declarações tendem a influir na satisfação de mais de uma necessidade, evidenciando a complexidade desta relação. As duas colunas da direita da Tabela 1 mostram a importância das declarações, baseando-se no somatório das importâncias dos relacionamentos e na contagem de relações. Já as duas últimas linhas da Tabela 1 mostram a importância de cada necessidade. Verifica-se que as necessidades derivadas mais importantes foram: ganhar tempo na escolha, escolher o filme que se gosta e ser visto como indivíduo.

Com base nas declarações mais importantes constantes da Tabela 1, dezenove atributos foram extraídos e pesquisados neste trabalho: 1) variedade de filmes; 2) sugestão de acordo com o perfil do cliente; 3) destaque para lançamentos; 4) boletim informativo sobre lançamentos; 5) site na internet; 6) localização próxima de casa; 7) os funcionários conhecerem filmes para darem sugestões; 8) organização dos filmes por tema; 9) cortesia no atendimento; 10) aviso quando está locando filmes já vistos; 11) estacionamento; 12) loja de conveniência; 13) caixa coletora; 14) TV com cenas dos filmes; 15) PC para consulta cadastral e para assistir trailers; 16) localização junto ao supermercado; 17) espaço para recreação infantil; 18) cartão fidelidade; e 19) existência de livraria/cybercafé. "Ter filmes disponíveis" não foi um atributo associado na pesquisa devido a uma falha na elaboração do questionário. "Caixa coletora" foi o atributo escolhido para satisfazer as declarações de horário de atendimento ampliado, inclusive para devolução até mais tarde. "PC para consulta cadastral" e "cartão fidelidade" foram atributos escolhidos para satisfazer a declaração de atendimento personalizado. Os atributos "espaço para recreação infantil" e "existência de livraria/cybercafé" foram incluídos deliberadamente por não existirem nas videolocadoras da região e representarem inovações. 
Tabela 1. Extração de necessidades e atributos. Fonte: os autores.

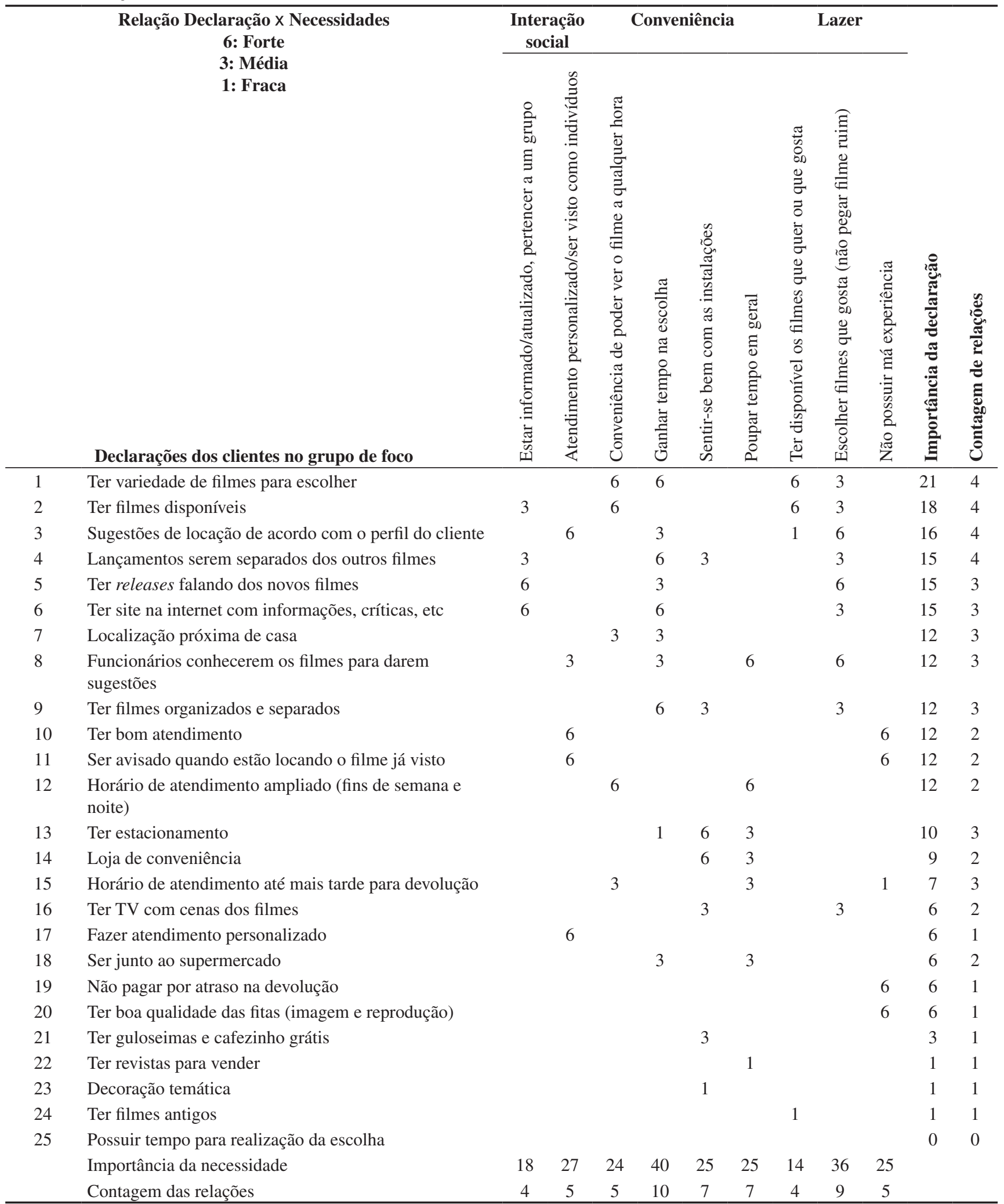

Assim, pretende-se avaliar como os atributos inovadores são identificados pelo método proposto.

O questionário de pesquisa, adaptado a partir das contribuições de Tontini e Silveira (2005), foi composto de quatro partes. Na primeira, os respondentes avaliaram sua satisfação diante de situações imaginárias de suficiência e insuficiência no desempenho de cada atributo, através de um questionário modificado do Modelo Kano. A Tabela 2 mostra um exemplo dessas questões para o atributo "caixa coletora", pesquisado neste trabalho. 
A questão de suficiência (ou existência) do atributo será chamada neste trabalho de Kano+, e a questão de insuficiência (ou inexistência) de Kano-. Tontini e Silveira (2005) propõem um questionário utilizando uma escala variando de muito insatisfeito a muito satisfeito, atribuindo um valor numérico variando de -3 (muito insatisfeito) a +3 (muito satisfeito) para cada resposta. Neste trabalho, utilizou-se uma escala de -4 (extremamente insatisfeito) até +4 (extremamente satisfeito), conforme Tabela 2, para ampliar as chances do cliente expressar seu nível de satisfação, aumentando o poder de discriminação entre os atributos. Para evitar simetria nas respostas, as perguntas positivas e negativas foram dispostas em ordem aleatória no questionário.

Em seguida, usando a mesma escala da Tabela 2, pediu-se aos respondentes que marcassem sua satisfação com o desempenho atual dos atributos pesquisados nas video locadoras que mais freqüentavam. Na terceira parte, a importância de cada atributo foi avaliada em uma escala de 1 a 5, sendo 1 "sem importância" e 5 "extremamente importante". Por último, pediu-se a satisfação geral com a videolocadora mais freqüentada e alguns dados demográficos. Um pré-teste com 20 respondentes foi realizado para ajustes do questionário. Durante a aplicação da pesquisa, questionários com respostas inválidas e inconsistentes foram sendo eliminados.

\section{Resultados e discussão}

A Figura 1 mostra a distribuição das cinco videolocadoras mais freqüentadas entre os 240 respondentes. Quarenta e quatro respondentes (18,3\% da amostra) freqüentam a Vídeo A ou a Vídeo B. Quarenta respondentes freqüentam as locadoras $\mathrm{C}, \mathrm{D}$ e $\mathrm{E}$.

Os outros 156 respondentes freqüentam outras 65 videolocadoras de diferentes localidades. A pulveri-

Tabela 2. Questionário Modificado do Modelo Kano. Fonte: autores.

\begin{tabular}{|c|c|c|c|c|c|c|c|c|c|}
\hline $\begin{array}{l}\text { Indique como você se } \\
\text { sentiria em relação a } \\
\text { uma vídeo locadora se } \\
\text { esta }\end{array}$ & 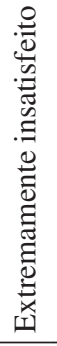 & 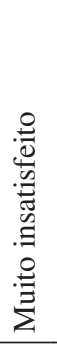 & 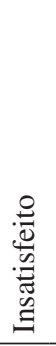 & 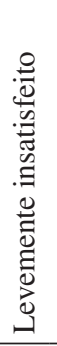 & $\begin{array}{l}\stackrel{0}{0} \\
0 \\
0 \\
0 \\
.0 \\
.0 \\
0 \\
0 \\
0 \\
0 \\
0 \\
0 \\
Z\end{array}$ & 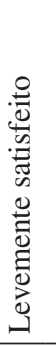 & 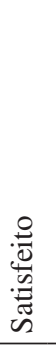 & 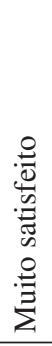 & 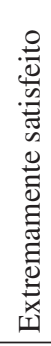 \\
\hline $\begin{array}{l}\text { Tiver caixa coletora } \\
\text { para devolução após } \\
\text { horário de atendimento. }\end{array}$ & -4 & -3 & -2 & -1 & 0 & 1 & 2 & 3 & \\
\hline $\begin{array}{l}\text { Não tiver caixa coletora } \\
\text { para devolução após } \\
\text { horário de atendimento. }\end{array}$ & -4 & -3 & -2 & -1 & 0 & 1 & 2 & 3 & \\
\hline
\end{tabular}

zação das videolocadoras freqüentadas pode representar a importância da localização das mesmas, próximas à residência, ao trabalho ou aos locais por onde os clientes passam freqüentemente.

No momento desta pesquisa, a Vídeo B tinha sido inaugurada há pouco tempo, disputando, devido a sua proximidade, a mesma fatia de mercado com a Vídeo A. Assim, deste ponto em diante, as análises serão feitas para a Vídeo A, comparando-se ora com o mercado ora com a Vídeo B (a mais forte concorrente da Vídeo A).

\subsection{Análise pela matriz de importância $x$ desempenho}

A análise de importância e desempenho, proposta por Martilla e James (1977), permite aos dirigentes das empresas terem uma visão sobre quais atributos do seu produto ou serviço deveriam ser melhorados, para tornarem-se mais competitivos no mercado. Geralmente, dados provenientes de pesquisas sobre satisfação do consumidor são utilizados para construir uma matriz bidimensional, na qual a importância é mostrada pelo eixo y e o desempenho do atributo pelo eixo x (Figura 2). A matriz é dividida em quatro quadrantes. $\mathrm{O}$ atributo que se situar no Quadrante I terá alta importância, com alto desempenho, representando assim uma possível vantagem

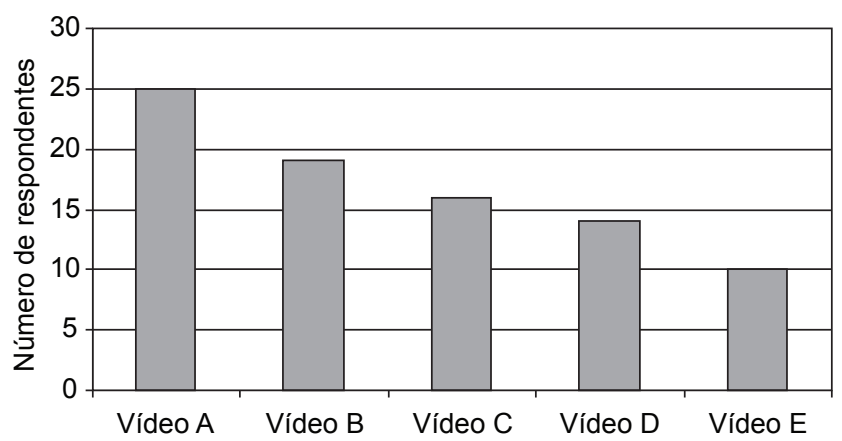

Figura 1. Distribuição das Videolocadoras freqüentadas. Fonte: os autores.

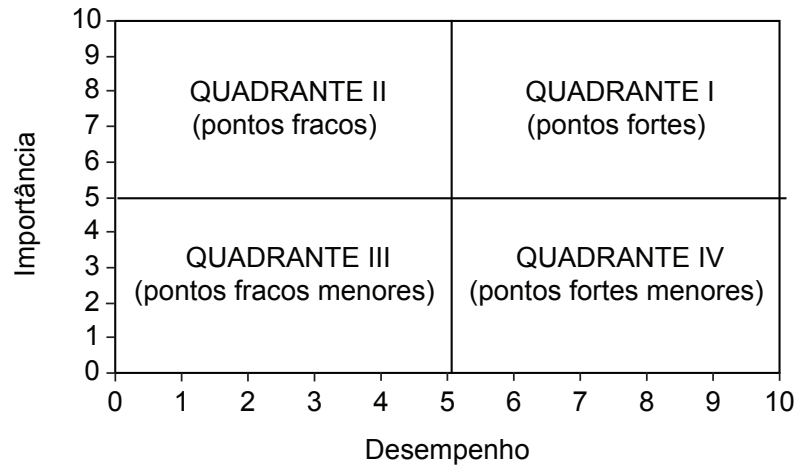

Figura 2. Matriz de importância $x$ desempenho. Fonte: Garver, 2003. 
competitiva. Neste caso, a empresa deve "manter o bom trabalho". Um atributo que tiver alta importância, mas baixo desempenho, deverá receber atenção imediata (Quadrante II). Para aumentar a satisfação geral, os dirigentes da empresa deveriam concentrar-se para melhorá-lo. O Quadrante III contém os atributos com baixa importância e baixo desempenho, não sendo necessário concentrar esforço adicional neles. O Quadrante IV apresenta os atributos com alto desempenho, porém com baixa importância. Neste caso, a empresa pode estar desperdiçando recursos que poderiam ser melhor aproveitados com outras aplicações.

O eixo de desempenho da matriz pode ser elaborado com dados de desempenho absoluto ou relativo à concorrência. Já a importância, pode ser determinada pela importância declarada ou pela importância derivada estatisticamente (GARVER, 2003). Na importância declarada, os consumidores tendem a dar alta importância para quase todos os atributos, havendo pouca discriminação entre eles. Já na importância derivada estatisticamente, o poder de discriminação entre os atributos é maior, porém o método pressupõe que haja uma relação linear entre a satisfação com os atributos e a satisfação geral, e que os respondentes tenham tido experiência com diferentes níveis de desempenho dos atributos (TONTINI; SILVEIRA, 2005).
Neste trabalho, o desempenho é representado pela razão entre a satisfação média com cada atributo para as videolocadoras A e B, respectivamente, sendo a linha divisória estabelecida em 1 (satisfação média igual entre Video A e B). Já a importância é estabelecida pela importância declarada, sendo a linha divisória estabelecida em 3, em uma escala de 1 a 5. A Figura 3 mostra a matriz de importância e desempenho para a videolocadora A. A zona de paridade foi estabelecida pelo teste $t$ para diferenças entre as médias, considerando variâncias equivalentes, com o valor de $\mathrm{p}<0,1$. A variância equivalente foi confirmada pelo teste de Levene para homogeneidade da variância com p-value $>0,1$ para todos os atributos e para a satisfação geral com as videolocadoras A e B. A exceção à zona de paridade deve ser feita para o atributo 9 - Organização Temática, cujo teste estatístico mostra diferença significativa entre as videolocadoras com um valor $\mathrm{p}<0,05$, mesmo aparecendo dentro da zona de paridade.

Analisando a Figura 3, verifica-se que a Vídeo A não tem nenhum ponto forte em relação à Vídeo B. Como pode-se observar, a Vídeo A tem igual desempenho quando comparada à $\mathrm{B}$ em atributos de alta importância, tais como: variedade, cortesia e organização temática dos filmes. Porém, ela está sendo avaliada com desempenho inferior em atributos de alta importância, como: conhecimento dos funcionários sobre os filmes, destaque

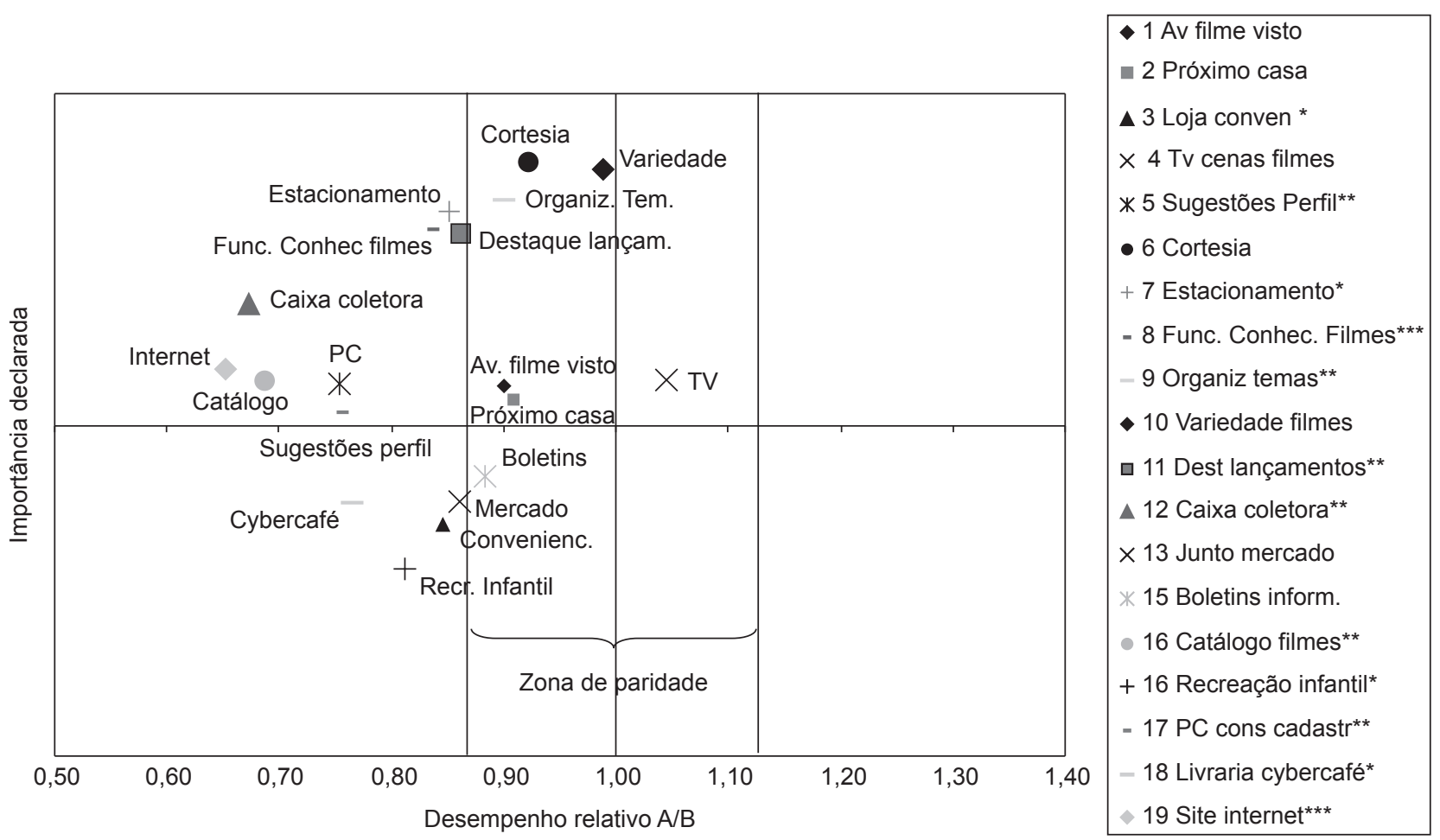

Figura 3. Matriz de importância $\mathrm{x}$ desempenho para os Atributos das Videolocadoras. $* \mathrm{p}<0,1$; $* * \mathrm{p}<0,05$; e $* * * \mathrm{p}<0,01$. Fonte: os autores 
para lançamentos, estacionamento e organização temática. A avaliação inferior em destaque para lançamentos e a Organização Temática pode estar ocorrendo devido à carência de espaço na Vídeo A. Já a avaliação inferior, que se relaciona ao estacionamento, pode ter ocorrido devido ao fato deste ser cobrado, por estar localizado em um shopping center.

Um outro grupo, com menor importância, porém ainda no campo de pontos fracos para a Vídeo A, aparece com os atributos: caixa coletora, site na internet, cartão fidelidade, sugestão de acordo com o perfil dos clientes e PC para consulta cadastral. Apesar da menor importância, estes podem ser os atributos que estão trazendo o diferencial para a Vídeo $\mathrm{B}$, explicando seu rápido crescimento. Os atributos: cybercafé, espaço para recreação infantil, localização junto ao mercado, loja de conveniência e boletins informativos foram considerados sem importância pelos respondentes.

Os resultados da Matriz de importância $x$ desempenho são confirmados pelo resultado da pergunta sobre a satisfação geral. A satisfação média geral com a Vídeo A é de 2,18, sendo que para a Vídeo B é de 2,78. Fazendo um teste $\mathrm{t}$ para a diferença entre as médias e considerando variâncias equivalentes, a satisfação com a Vídeo A é menor que a satisfação com a Vídeo B, cujo valor é de $\mathrm{p}=0,001$.

Tendo em vista a posição dos atributos na Matriz de importância $x$ desempenho, a Vídeo A deveria melhorar a variedade, a cortesia e o conhecimento dos funcionários sobre os filmes, os quais são atributos de alta importância e com desempenho igual ou inferior à Vídeo B. Já os atributos organização temática e destaque para lançamentos devem ser melhorados na medida do possível, dado o espaço disponível. Quanto ao estacionamento, por estar fora de seu controle, a Vídeo A não tem muito a fazer, exceto se mudasse para outro local ou se pagasse o estacionamento para os seus clientes, o que encareceria a locação.

Os atributos caixa coletora, site na internet, PC para consulta cadastral e sugestões de acordo com o perfil do cliente, deveriam ser avaliados para introdução, pois apesar de serem de menor importância, podem representar atributos atrativos, o que faz o diferencial. Como será visto a seguir, na análise do Modelo Kano, atributos atrativos têm a tendência de serem considerados de menor importância pelo consumidor.

\subsection{Modelo Kano de qualidade atrativa e obrigatória}

O Modelo Kano de Qualidade Atrativa e Obrigatória (KANO et al., 1984; BERGER et al., 1993; MATZLER et al., 1996) traz uma perspectiva diferente para a análise de oportunidades de melhoria, pois leva em consideração a relação não linear entre desempenho e satisfação. $\mathrm{O}$
Modelo Kano faz distinção entre três tipos de atributos que influenciam a satisfação do cliente (Figura 4):

a) Atributos obrigatórios: Também chamados de atributos básicos, preenchem as funções básicas de um produto. Se eles não estiverem presentes ou se o desempenho for insuficiente, os clientes ficarão extremamente insatisfeitos. Por outro lado, se estiverem presentes ou tiverem desempenho suficiente, eles não trazem satisfação. Os clientes vêem esses atributos como pré-requisitos. Por exemplo, a limpeza é considerada um item obrigatório ou básico em restaurantes. Um cliente não se sentirá satisfeito se o restaurante estiver limpo, porém deixará de freqüentá-lo se a limpeza for abaixo de um determinado nível;

b) Atributos unidimensionais: Também chamados de atributos de desempenho. Quanto a estes atributos, a satisfação é proporcional ao nível de desempenho - quanto maior o nível de desempenho, maior será a satisfação do cliente e vice-versa. O consumo de combustível dos automóveis é um exemplo de atributo nesta categoria. Usualmente os consumidores demandam esses atributos explicitamente; e

c) Atributos atrativos: Também chamados de excitantes, estes atributos são pontos-chave para a satisfação do cliente. Se tiverem alto desempenho trarão satisfação superior. Porém, eles não trazem insatisfação se não forem atendidos. Por exemplo, se ao final de um jantar um restaurante oferece uma "lembrança" adicional aos seus clientes, isto certamente trará satisfação. Se o presente não for oferecido, não trará insatisfação. Atributos atrativos não são nem expressos explicitamente e nem esperados pelo cliente.

Dois outros tipos de atributos podem ser identificados no Modelo Kano: neutros e reversos. Atributos neutros

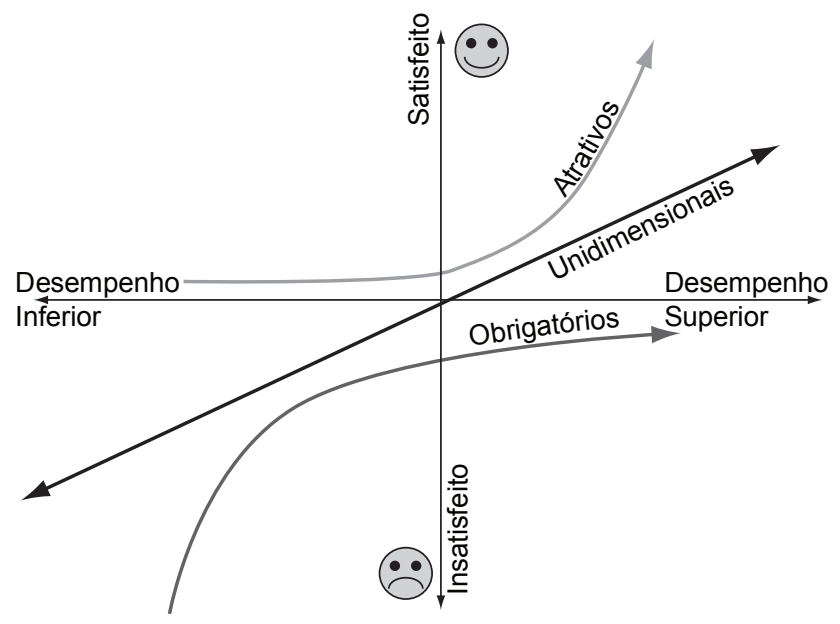

Figura 4. Modelo Kano de Qualidade Atrativa e Obrigatória. Fonte: adaptado de Matzler et al, 1996. 
não trazem satisfação ou insatisfação. Atributos reversos trazem mais satisfação se ausentes.

Kano et al. (1984), Berger et al. (1993) e Matzler et al. (1996) sugerem que os atributos obrigatórios, unidimensionais e atrativos podem ser identificados perguntando-se aos consumidores sobre sua reação ou satisfação, quando os atributos têm desempenho superior (questão positiva) e inferior (questão negativa). Dependendo das respostas para a questão "positiva" e "negativa", o atributo pode ser identificado como atrativo, obrigatório, unidimensional, neutro ou reverso.

O Modelo Kano introduz questionamentos sobre a utilização da análise de importância $x$ desempenho para a identificação de oportunidades de melhoria em bens e serviços. De maneira geral, Sauerwein (1999) demonstra que o consumidor tende a dar maior importância aos atributos obrigatórios, decrescendo esta importância aos unidimensionais, atrativos e neutros, respectivamente. Como um desempenho superior em atributos obrigatórios não causa satisfação superior, a análise da importância $x$ desempenho pode levar uma empresa a concentrar esforços em atributos cuja melhoria não trará grandes incrementos na satisfação geral. Já a baixa importância dada aos atributos atrativos pode levar uma empresa a não melhorar aspectos que poderiam fazer o diferencial em relação à concorrência.

Além da tendência em se dar maior importância aos atributos básicos, Matzler et al. (2004), analisando a importância derivada estatisticamente para atributos com alto ou baixo desempenho, demonstram que a importância pode variar com o desempenho. Para atributos básicos, a importância decresce quando o desempenho é alto. Já para os atributos excitantes, a importância tende a subir quando o desempenho é alto, porque o cliente já experimentou os benefícios daquele atributo e acostumou-se a eles. Isto leva a outra constatação: a importância será menor quanto mais desconhecido ou inovador for um atributo. Assim, inovações são raramente introduzidas se a análise for baseada apenas na importância e no desempenho, pois o desconhecimento dos benefícios, que poderão ser trazidos por uma inovação, leva o cliente a considerá-la como não importante. Retornando à Figura 3 , verifica-se que os atributos inovadores, Livraria/cybercafé e Espaço para recreação infantil foram classificados como neutros. Esta classificação pode ser ocasionada por duas razões: pelos atributos serem realmente neutros para os respondentes da pesquisa ou por serem desconhecidos.

Matzler et al. (2004) estudam a influência do desempenho na avaliação da importância derivada estatisticamente. Porém, fica a pergunta: a importância declarada também é influenciada pelo desempenho atual dos atributos? A Figura 5 mostra um gráfico de corre- lação entre a importância declarada e a satisfação média com os atributos entre os 240 respondentes.

Como se pode ver pela Figura 5, existe uma relação de dependência. Em geral, quanto maior a satisfação, maior a avaliação de importância média. A dispersão aumenta quando a satisfação se aproxima a zero (o meio da escala de $-4 \mathrm{a}+4)$. Isto pode ocorrer devido ao fato de nesta zona haver dois tipos de atributos: aqueles em que o respondente é indiferente, que então terão satisfação neutra (zero), e aqueles que possuem consumidores insatisfeitos e satisfeitos, levando a média para próxima de zero.

Apesar do Modelo Kano trazer uma visão diferente sobre o efeito do desempenho dos atributos na satisfação do consumidor, ele não leva em consideração o nível atual de desempenho dos mesmos. Como a posição competitiva não é levada em consideração, o Modelo Kano, usado de maneira isolada, também é limitado como um direcionador dos esforços de melhoria (TONTINI; SILVEIRA, 2005).

\section{Análise competitiva dos gaps de melhoria}

Para direcionar os esforços de melhoria é primordial que seja avaliada a situação atual, isto é, quão satisfeitos estão os clientes com os atuais competidores no mercado, e qual a posição competitiva da empresa em relação aos concorrentes. Ainda, deve-se procurar determinar qual a satisfação adicional que poderá ser conseguida pela melhoria de um atributo. No método aqui proposto, os valores médios de satisfação com o desempenho superior $($ Kano +) e inferior (Kano -) são comparados ao valor médio de satisfação atual com o atributo no mercado, e os gaps de satisfação com o aumento ou diminuição no desempenho dos atributos são assim calculados. Desta maneira, segundo Tontini e Silveira (2005), fica claro o ganho ou a perda de satisfação proporcionada por

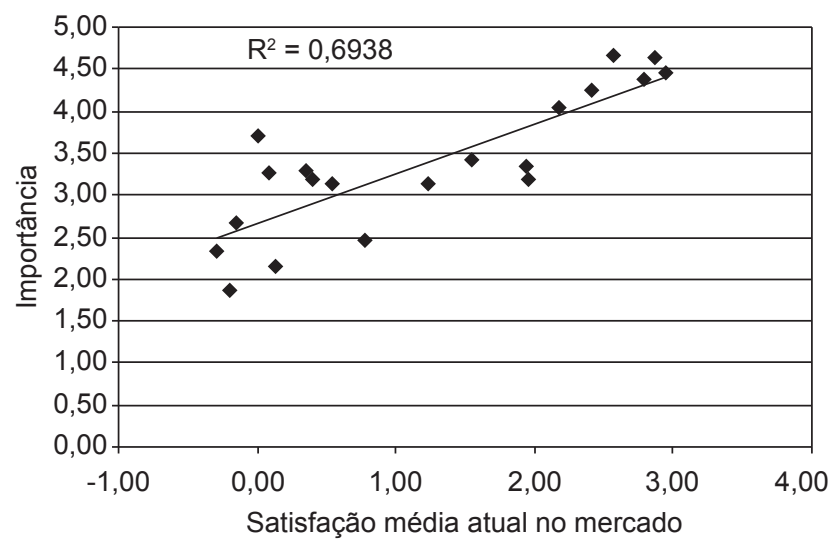

Figura 5. Correlação satisfação $x$ importância declarada para os atributos das videolocadoras. Fonte: os autores. 
um aumento ou por uma diminuição no desempenho do atributo. Por exemplo, neste trabalho, a satisfação média esperada, se a videolocadora tiver atendimento gentil e cortês (Kano+) é de $+2,97$. Já a satisfação média se a videolocadora não tiver atendimento gentil e cortês (Kano-) é de -3,33. A satisfação média atual de todos os respondentes com a gentileza e cortesia das videolocadoras é de 2,86. Então, o gap positivo será $2,97-2,86=0,11$ e o gap negativo será $2,86-(-3,33)$ $=6,19$. Assim, melhorar a gentileza e a cortesia, acima do nível médio atual de mercado, não aumentará muito a satisfação dos clientes. Já abaixo deste nível causará um grande decréscimo no nível de satisfação.

Para melhor visualização, os gaps de satisfação com o aumento ou diminuição no desempenho dos atributos são plotados em um gráfico. A Figura 6 mostra um gráfico de barras com os gaps de satisfação para os atributos estudados neste artigo. O gráfico apresenta duas barras para cada atributo. Uma barra para o incremento de satisfação esperado com a melhora ou oferta do atributo (gap positivo) e outra para o decréscimo de satisfação esperado pela piora ou ausência do atributo (gap negativo).

Apesar do método proposto por Tontini e Silveira (2005) ser um avanço sobre a análise da Matriz de importância X desempenho, ele ainda apresenta limitações. Uma limitação diz respeito aos gaps positivo e negativo. Como o consumidor tende a ter algum nível de satisfação média positiva com o desempenho atual dos atributos, e como avalia as situações negativas de maneira extrema, existe a tendência do gap negativo ser maior que o gap positivo, como pode ser visto pela Figura 6. Isto pode mascarar a identificação da classificação dos atributos dentro do

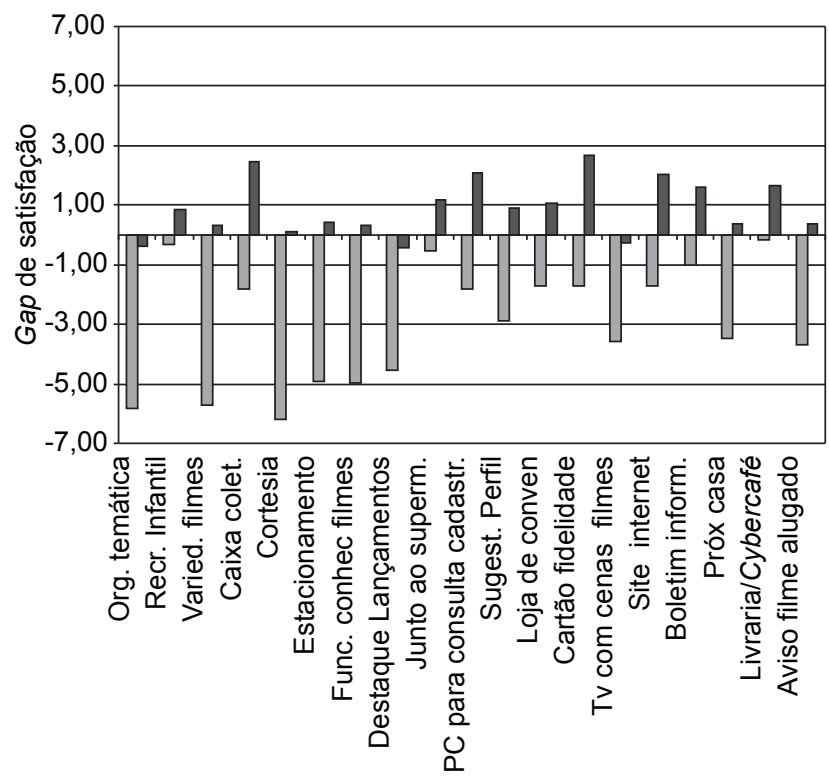

Figura 6. Gaps de melhoria absoluta dos atributos das video locadoras. Fonte: os autores.
Modelo Kano, havendo assim um aumento de atributos classificados como unidimensionais ou obrigatórios.

Uma maneira de diminuir o viés do gap negativo é subtrair deste gap a média atual de satisfação com o atributo. Assim, o gap positivo é dado pelo incremento de satisfação que a melhoria do atributo trará em relação à média atual (Kano Positivo - Média atual). O gap negativo é dado pelo valor absoluto de insatisfação gerada pela ausência ou insuficiência do atributo. Por exemplo, para o caso do atributo "cortesia e gentileza", o gap positivo seria $2,97-2,86=0,11$. Já o gap negativo corrigido será dado pelo valor absoluto de satisfação $(-3,33)$, com a ausência ou insuficiência do atributo.

A Figura 7 mostra um gráfico de barras com os gaps positivos e negativos corrigidos para os 19 atributos estudados. Além dos gaps corrigidos, a Figura 7 mostra o gap entre a satisfação média com a Vídeo A, a Vídeo B e a média do mercado. Como se pode verificar, a assimetria dos gaps foi diminuída e os atributos podem ser classificados de acordo com o Modelo Kano. Atributos, cujos gaps positivo e negativo encontram-se dentro das linhas de neutralidade são considerados neutros.

As linhas divisórias de neutralidade foram estabelecidas em $\pm 1,5$. Isto é, atributos que apresentam incremento de satisfação maior que 1,5 são considerados relevantes para a melhoria ou a oferta. Já atributos que apresentam insatisfação média inferior a $-1,5$ com sua ausência são considerados significativos, pois são possíveis geradores de insatisfação geral. Não há regra específica para a definição do valor das linhas divisórias de neutralidade, porém o raciocínio por trás deste valor é que o incremento de satisfação com a melhora tem que ser maior que, por exemplo, passar de "levemente satisfeito" para "satisfeito". Já a ausência do atributo tem que gerar uma insatisfação maior que "levemente insatisfeito" para ser considerado significativo.

Pela Figura 7, os atributos organização dos filmes por tema, variedade de filmes, cortesia no atendimento, estacionamento, funcionários conhecerem filmes para darem sugestões, destaque para lançamentos, sugestões de acordo com o perfil do cliente, TV com cenas de filmes, proximidade de casa e avisar quando está locando filme já visto apresentam um impacto muito maior se tiverem desempenho diminuído (do que aumentado), podendo então ser classificados como obrigatórios pelo Modelo Kano. Entre estes atributos, os gestores da Vídeo A deveriam concentrar-se, em ordem de prioridade, naqueles que estão mais abaixo da média de mercado, que seriam os funcionários conhecerem os filmes e destaque para lançamentos (Figura 7). No atributo cortesia, a Vídeo A não apresenta diferença estatística significativa em relação à média do mercado e em relação à Vídeo $\mathrm{B}$, não sendo necessário melhorá-la devido ao fato de que um aumento em seu desempenho não trará grande incre- 


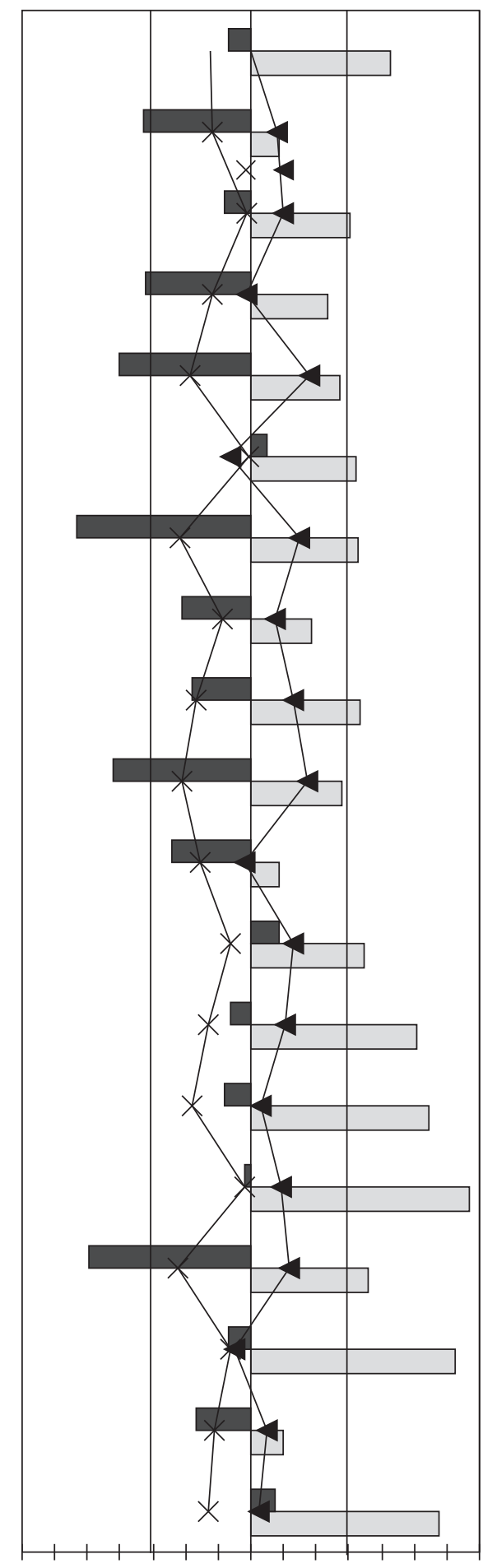

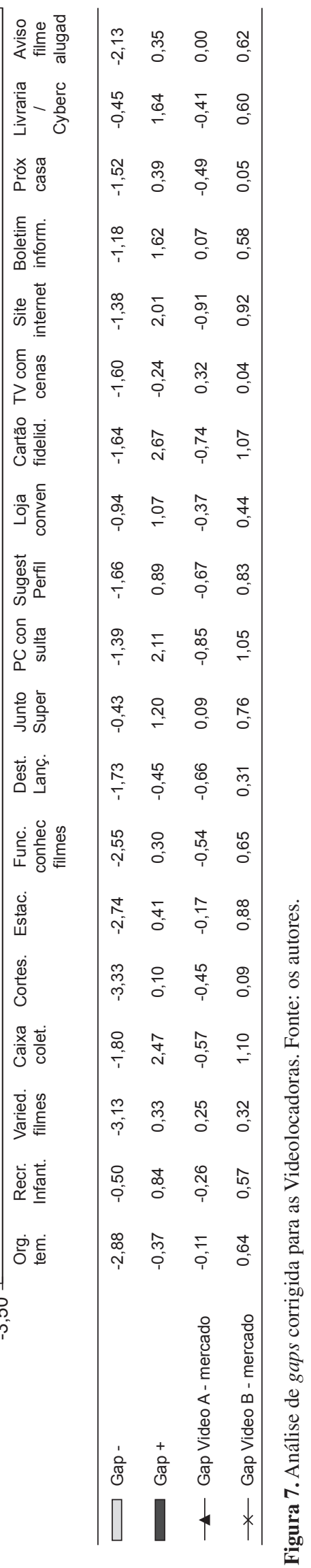

Gest. Prod., São Carlos, v. 14, n. 1, p. 43-54, jan.-abr. 2007 
mento na satisfação atual. Os atributos proximidade de casa e estacionamento fogem do controle da Vídeo A, a não ser que esta se mude para outro local.

Caixa coletora e cartão fidelidade podem ser considerados como unidimensionais pelo Modelo Kano, uma vez que trazem um aumento de satisfação se ofertados e também trazem um nível médio de insatisfação razoável se ausentes (Figura 7). Neste caso a Vídeo B está abaixo da média de mercado e também deveria melhorar. PC para consulta cadastral, site na internet e livraria/ cybercafé podem ser considerados atrativos, uma vez que trazem mais aumento de satisfação se presentes que insatisfação se ausentes. Entre os atributos unidimensionais e atrativos, devem-se destacar: cartão fidelidade, caixa coletora, PC para consulta cadastral, site na internet e livraria/cybercafé, devido ao grande impacto no aumento da satisfação, caso estejam presentes. Aqui, diferentemente da Matriz de importância $x$ desempenho, $o$ atributo inovador livraria/cybercafé foi considerado atrativo. Já local para recreação de crianças foi considerado neutro. Isto devido ao perfil dos respondentes da pesquisa, em sua grande maioria, sem filhos.

Analisando a Figura 7, pode-se ver que a Vídeo A não está melhor que o mercado em nenhum dos atributos estudados. Já com relação à Vídeo B, ela está com desempenho melhor ou igual ao mercado em todos os atributos, tendo maior gap em relação ao mercado justamente nos atributos considerados atrativos ou que trazem maior satisfação se presentes, o que pode indicar as razões de seu crescimento expressivo.

\section{Considerações finais}

Como consumidores satisfeitos tendem a repetir o consumo e são menos sensíveis aos preços, atender suas necessidades é fundamental para o sucesso de uma empresa no longo prazo (REICHHELD; SASSER, 1990). $\mathrm{O}$ atendimento dessas necessidades depende do desempenho do produto ou serviço em seus diversos atributos. Assim, a identificação da relação entre o desempenho dos atributos e a satisfação do consumidor torna-se chave para o sucesso em um mercado competitivo. Como as necessidades dos consumidores mudam constantemente devido aos costumes, aos movimentos dos competidores e à oferta de produtos substitutos, o trabalho de inovação e melhoria nos bens e serviços ofertados deve ser contínuo (TONTINI; SILVEIRA, 2005).

Um método utilizado para analisar os atributos de um produto ou serviço e verificar oportunidades de melhoria é a análise pela Matriz de importância $\mathrm{x}$ desempenho (MARTILLA; JAMES, 1977). Apesar de largamente utilizado, este método não leva em consideração a relação assimétrica e não-linear entre o desempenho dos atributos e a satisfação por eles proporcionada, podendo levar a decisões equivocadas. Uma decisão equivocada pode ser a realização de esforços para melhorar atributos considerados básicos pelo consumidor (geralmente considerados de alta importância), quando a empresa está com um desempenho igual ao dos competidores. Neste caso, ela estará desperdiçando recursos, pois a melhoria deste atributo não trará satisfação superior. Além disto, como atributos inovadores tendem a ser considerados de baixa importância pelos consumidores, pode-se deixar de introduzir uma inovação que poderia trazer um diferencial competitivo. Um outro possível problema da análise pela Matriz de importância $x$ desempenho é que (ao contrário do que o método pressupõe) começam a surgir evidências de que a importância varia com o desempenho dos atributos. Este trabalho identificou que nos atributos estudados nas videolocadoras, o consumidor tende a dar maior importância aos atributos que produzem maior satisfação.

O Modelo Kano de qualidade atrativa e obrigatória (KANO et al., 1984; BERGER et al., 1993; MATZLER et al., 1996) identifica a relação não-linear entre desempenho e satisfação, classificando os atributos como obrigatórios, unidimensionais e atrativos. Porém, o Modelo Kano original somente identifica a classificação dos atributos, não levando em consideração o desempenho atual do produto ou serviço no mercado. Assim, de maneira isolada, ele pouco pode ajudar no direcionamento dos esforços de melhoria.

Para tentar superar estas limitações, Tontini e Silveira (2005) propõem um método de análise das oportunidades de melhoria baseado no aumento ou decréscimo de satisfação, que seria ocasionada com a variação no desempenho dos diferentes atributos. Segundo os autores, o método foi capaz de identificar a classificação de quatro atributos de pizzarias dentro do Modelo Kano (inclusive um atributo inovador) e direcionou de forma adequada as decisões de melhoria.

Apesar de este método ser um avanço em relação à análise pela Matriz de importância X desempenho, ele ainda apresenta limitações. Uma dessas limitações diz respeito aos gaps positivo e negativo. Como o consumidor tende a ter algum nível de satisfação positiva com os atributos atuais e a avaliar as situações negativas de maneira extrema, há a tendência do gap positivo ser menor que o gap negativo, o que pode dificultar a identificação de atributos atrativos.

Como forma de superação desta limitação, este trabalho apresentou uma modificação no método proposto por Tontini e Silveira (2005) para identificação dos atributos dentro do Modelo Kano, fazendo uma correção no gap de decréscimo da satisfação com a insuficiência de desempenho, substituindo-o pelo valor absoluto de insatisfação média. O método proposto mostrou as oportunidades de melhoria em atributos de videolocadoras, revelando de maneira mais significativa atributos atrativos, unidi- 
mensionais e obrigatórios. Particularmente, um atributo inovador foi identificado pelo método proposto e desprezado pela Matriz de importância $x$ desempenho.

A constatação de que a importância pode variar com o desempenho dos atributos abre perspectivas para novas pesquisas com o objetivo de identificar se esta variação é confirmada em outros casos e como ela ocorre de acordo com a classificação dos atributos, segundo o Modelo Kano.

Uma limitação deste trabalho diz respeito ao grau de generalização das conclusões sobre os atributos das videolocadoras. Como a amostra dos respondentes da pesquisa foi composta por alunos de graduação em Administração, ela não representa uma amostra representativa de toda a população de clientes de videolocadoras. Assim, as conclusões realizadas sobre o efeito dos atributos na satisfação dos clientes e sobre as estratégias a serem utilizadas pela Vídeo A estão restritas à amostra pesquisada, não podendo ser generalizadas. Porém, a amostra utilizada serviu para ilustrar o método proposto, que por sua simplicidade, tem potencial para aplicação em pequenas ou grandes empresas, tanto no setor de serviços quanto na produção de bens.

\title{
Identifying critical attributes of satisfaction in a service using the competitive analysis of the improvement gap
}

\begin{abstract}
Using attributes of Video Rental Stores as a case study, this paper presents a method to identify satisfaction attributes and improvement opportunities in products and services in a competitive market, overcoming some of the limitations of the importance performance analysis proposed by Martilla and James (1977). The methodology was of an exploratory-descriptive type. The data collection was carried out in two steps. First, a focus group with 8 customers of video rental stores was carried out to identify the attributes to be used in the study. Then, 240 undergraduate students, customers of video rental stores, responded to a modified Kano Model questionnaire (Kano et al., 1984). The analysis of the attributes was done using a gap analysis derived from the method proposed by Tontini and Silveira (2005). Nineteen attributes were studied. From these, four were classified as attractive attributes; ten were classified as must-be (basic) attributes, two as one-dimensional and three as neutral ones. The Gap analysis proposed in this paper was able to identify basic and attractive attributes, making it possible to correctly identify improvement opportunities, overcoming limitations of the importance performance analysis and of the traditional Kano analysis.
\end{abstract}

Keywords: Kano model. Customer satisfaction. Service quality. Quality management.

\section{Referências bibliográficas}

ANDERSON, E. W.; MITTAL, V. Strengthening the SatisfactionProfit Chain. Journal of Service Research, Maryland, v. 3, n. 2, p. 107-129, nov. 2000.

BERGER, C. et al. Kano's methods for understanding customerdefined quality. Center for Quality Management Journal, Massachusetts, v. 2, n. 4, p. 3-35, fall 1993.

DESZCA, G.; MUNRO, H.; NOORI, H. Developing breakthrough products: challenges and options for market assessment. Journal of Operations Management, East Lansing, v. 17, n. 6, p. 613-630, nov. 1999.

GARVER, M. S. Best practices in identifying customerdriven improvement opportunities. Industrial Marketing Management, Vernon, v. 32, n. 6, p. 455-466, aug. 2003.

HUISKONEN, J.; PIRTTILÄ, T. Sharpening logistics customer service strategy planning by applying Kano's quality element classification. International Journal of Production Economics, Linköping, v. 56-57, p. 253-260, sept. 1998.
KANO, N., et al. Attractive quality vs must be quality. Journal of the Japanese Society for Quality Control, Tokyo, v. 14, n. 2, p. 39-48, 1984.

KAWAKITA, J. The Original KJ Method. Tokyo: Kawakita Research Institute, 1991.

MARTILLA, J. A.; JAMES, J. C. Importance-performance analysis. Journal of Marketing, New York, v. 41, n. 1, p. 77-79, jan. 1977.

MATZLER, K., et al. How to delight your customers. Journal of Product \& Brand Management, Santa Barbara, v. 5, n. 2, p. 6-17, mar. 1996.

MATZLER, K., et al. The asymmetric relationship between attribute-level performance and overall customer satisfaction: a reconsideration of the importance-performance analysis. Industrial Marketing Management, Vernon, v. 33, n. 4, p. 271-277, may 2004 . 
MIZUNO, S. Gerência para melhoria da qualidade: as sete novas ferramentas de controle da qualidade. Rio de Janeiro: Livros Técnicos e Científicos, 1993, 282 p.

REICHHELD, F. F.; SASSER, W. E. Zero-Defections: Quality Comes to Services. Harvard Business Review, Boston, v. 68, n. 5, p.105-111, sept./oct. 1990.

SHIBA, S. The Language Processing Method. Document ML0060. Boston: The Center for Quality Management, 1994.
SAUERWEIN, E. Experiences with the Reliability and Validity of the Kano-Method: Comparison to Alternate Forms of Classification of Product Requirements. In: SYMPOSIUM ON QFD, 11, 1999, Michigan. Transactions... Michigan: QFD Institute, 1999, p. 1-14.

TONTINI, G.; SILVEIRA, A. Identification of Critical Attributes of Success in Products and Services: an Alternative to Importance Performance Analysis. In: BALAS ANNUAL CONFERENCE, 2005, Madrid. Proceedings... Madrid: Instituto de Empresa, 2005, p. 1-20.

\section{Sobre os autores}

\section{Gérson Tontini}

\section{André José Sant ana}

Grupo de Pesquisa em Estratégia e Competitividade de Organizações,

Programa de Pós-graduação em Administração, Departamento de Administração,

Centro de Ciências Sociais Aplicadas, Universidade Regional de Blumenau,

Rua Antônio da Veiga 140, Centro, CEP 89012-900, CP 140, Blumenau, SC, Brasil,

e-mails: tontini@furb.br, andrerj@furb.br 